\title{
Kawasaki disease: what the paediatrician needs to know
}

\author{
Nicole Ritz ${ }^{1,2}$
}

Published online: 27 June 2017

(C) Springer-Verlag Berlin Heidelberg 2017

In January 1961, Dr. Tomisaku Kawasaki saw his first case of a 4-year-old boy with what is now known as Kawasaki disease. He described this boy as having a "unique symptom complex" he had never seen before and had to discharge the boy with an unknown diagnosis [5]. Over the next 5 years, Dr. Kawasaki recognised additional similar cases, which he meticulously documented and published in 1967 under the lengthy name of "Febrile oculo-oro-cutaneo-acrodesquamatous syndrome with or without acute non-suppurative cervical lymphadenitis in infancy and childhood" [3].

Today, Kawasaki disease together with rheumatic heart disease are the leading causes of acquired heart disease in children [6]. Despite this, clinical recognition of Kawasaki disease in children with a prolonged febrile illness remains challenging - particularly in those with incomplete Kawasaki disease where fewer than four of the principal clinical findings manifest. In this issue of the European Journal of Paediatrics, Dietz et al. present a concise update on the current diagnostic criteria for Kawasaki disease including for children presenting with incomplete Kawasaki disease [2]. This review may also be read in parallel with the most recent update of the scientific statement by the American Heart Association on diagnosis, treatment, and long-term management of Kawasaki disease [4].

This Editorial refers to the article http://dx.doi.org/10.1007/s00431-0172937-5.

Nicole Ritz

Nicole.ritz@unibas.ch

1 Paediatric Infectious Diseases and Vaccinology and Paediatric Pharmacology and Pharmacometrics, University of Basel Children's Hospital, Spitalstrasse 33, 4031 Basel, CH, Switzerland

2 Department of Paediatrics, The University of Melbourne, Parkville, VIC, Australia
While significant progress has been made in understanding the epidemiology and clinical aspects of Kawasaki disease over the last 50 years, many aspects regarding aetiology, immunology and host genetics remain unanswered. Dietz et al. seek to summarise recent advances in this state-of-the-art review [2]. Further, an increasing number of patients with Kawasaki disease now reach adulthood, and as a result, long-term prognosis has become an important discussion point for all specialists caring for these patients [1]. A succinct summary of data on long-term follow-up in patients with Kawasaki disease including their cardiovascular risk, issues surrounding quality-of-life, and its impact on social behaviour is provided and will be helpful for discussion with patients and families.

\section{References}

1. Dietz SM, Tacke CE, de Groot E, Kuipers IM, Hutten BA, Kuijpers TW (2016) Extracardial vasculopathy after Kawasaki disease: a long-term follow-up study. J Am Heart Assoc 5:e003414

2. Dietz SM, van Stijn D, Burgner D, Levin M, Kuipers IM, Hutten BA, Kuijpers TW (2017) Dissecting Kawasaki disease: a state-of-the-art review. Eur J Pediatr doi:10.1007/s00431-017-2937-5

3. Kawasaki T (2002) Pediatric acute febrile mucocutaneous lymph node syndrome with characteristic desquamation of fingers and toes: my clinical observation of fifty cases*. Pediatr Infect Dis J 21:1-38

4. McCrindle BW, Rowley AH, Newburger JW, Burns JC, Bolger AF, Gewitz M, Baker AL, Jackson MA, Takahashi M, Shah PB, Kobayashi T, Wu MH, Saji TT, Pahl E, American Heart Association Rheumatic Fever E, Kawasaki Disease Committee of the Council on Cardiovascular Disease in the Y, Council on C, Stroke N, Council on Cardiovascular S, Anesthesia, Council on E, Prevention (2017) Diagnosis, treatment, and long-term management of Kawasaki disease: a scientific statement for health professionals from the American Heart Association. Circulation 135:e927-e999

5. Saji BT, Newburger JW, Burns JC, Takahashi M (2017) Kawasaki Disease. Springer

6. Singh S, Vignesh P, Burgner D (2015) The epidemiology of Kawasaki disease: a global update. Arch Dis Child 100:1084-1088 